\title{
CURBSIDE RECYCLING IN THE U.S.A.: CONVENIENCE AND MANDATORY PARTICIPATION
}

\author{
Jess W. Everett* and J. Jeffrey Peirce $\dagger$ \\ * School of Civil Engineering and Environmental Science, University of Oklahoma, Norman, \\ Oklahoma, 73019-0631, U.S.A. and $\dagger$ Department of Civil and Environmental Engineering, Duke \\ University, Durham, North Carolina, 27706, U.S.A.
}

(Received 15 May 1991, accepted in revised form 16 May 1992)

\begin{abstract}
This research examines the relationship between the success of a residential curbside recycling program (RCRP), measured as material recovery rate (MRR), and two program factors: (1) whether or not participation is mandated; and (2) convenience, measured by container provision, collection frequency and collection day relative to municipal solid waste collection day. Residential curbside recycling programs, with correct strategies and program design, can be an important part of solid waste management plans world-wide. While residential curbside recycling programs are growing in popularity, many basic design questions lie unanswered and successful program strategies are not always obvious. Data from 357 residential curbside recycling programs in the United States are used to test the hypotheses. Mandatory participation residential curbside recycling programs are seen to collect more material than voluntary participation residential curbside recycling programs. Container provision appears effective for voluntary, but not mandatory, residential curbside recycling programs. Increasing collection frequency appears to have a small positive effect on residential curbside recycling program success, while collection day has little effect on material recovery rate.
\end{abstract}

Key Words-U.S.A., curbside recycling, recycling, residential recycling, municipal solid waste, material recovery, mandatory recycling, questionnaire survey.

\section{Introduction and objectives}

Public participation programs addressing environmental problems typically incorporate physical process components including collection, transport and processing or disposal of waste, and may also include social components designed to mobilize persons to properly deliver, store and handle specific wastes. Social components attempt to mobilize individuals to perform personally inconvenient actions which produce benefits often delivered to all members of the group serviced by the program, regardless of individual contribution level.

Residential curbside recycling programs (RCRPs) contain both physical and social components; but many design component questions lie unanswered. Furthermore, as population and resource pressures increase, the need for RCRPs increases. Many states in the U.S.A. already are experiencing disposal problems (ASTSWMO 1987), the U.S. Environmental Protection Agency (EPA) has stated a goal of $25 \%$ reduction of solid waste through source reduction or recycling (USEPA 1989), and legislative action concerning solid waste issues has been intense in the last few years (Bell et al. 1990).

As of 1990, over 2700 RCRPs were operating in the U.S. (Glenn \& Riggle 1991). But 
while RCRPs are an important part of many solid waste management solutions (Walsh \& O'Leary 1988a), there is currently little systematic knowledge of what material recovery can be expected from RCRPs given the various possible design strategies (Lund 1990). In designing RCRPs, the environmental engineer would be greatly assisted by information of this nature. The goal of this paper is to provide data on the effectiveness of program design parameters concerning mandatory participation and recycling convenience. The specific objectives are:

(1) review historically reported participation requirement and convenience factors influencing residential curbside recycling program success;

(2) develop specific hypotheses concerning mandatory participation, container provision, collection frequency and collection on the same day as municipal solid waste;

(3) test these hypotheses using data from a nationwide survey of residential curbside recycling programs; and

(4) make conclusions pertaining to the relative merits of the various design parameters.

\section{Reported factors influencing recycling program success}

Designing RCRPs to maximize material recovery and, by implication, participation involves: acting on predispositions and community structures favorable to recycling; increasing recycling program awareness and acceptance through education and promotion; and directly encouraging participation by various devices such as economic inducements, legislation and elements designed to increase convenience. In this paper, participation requirements and convenience are explored. Elsewhere the authors have addressed the issues of community structure and education and promotion (Everett $\&$ Peirce $1991 a, b$ ). Most of the recycling programs analysed in this paper used education and promotion to encourage recycling behavior in 1987 and 1988 . However, it is difficult to incorporate information on educational and promotional activities into the analyses used here because of the large variation in types of promotions used and frequency of use. Also, the quality of the materials used may have varied greatly, but was not measured in this study, because of the large cost involved in collecting, examining and judging program materials. The absence of educational and promotional data introduces uncertainty into the analyses. However, as no trends were observed-for example, mandatory programs did not appear to promote more than voluntary programs and so forth - the absence of education and promotion data from the analyses presented in this paper should not adversely affect the results.

In the following sections, information gathered from a review of the literature, concerning recycling and participation requirements, container provision, collection frequency and collection day, is presented. Studies conducted in these areas are fairly rare and have generally been conducted on a few programs, often by operating two pilot programs in one community and varying parameters between the two. For example, one pilot program might collect on the same day, and the other on a different day, than the MSW collection. The authors have identified no studies where sufficient data, from a large enough number of programs to allow for statistical comparison, have been collected.

\subsection{Mandatory versus voluntary participation}

About $50 \%$ of all RCRPs in the U.S. require residents, by law, to recycle selected materials. Mandatory program numbers have increased from 42 in 1979 to at least 592 in 
1989 (Glenn 1990, Cooper 1982) and reports of the increase in material recovery of mandatory recycling compared to voluntary vary from 30 to $100 \%$ (for example, Allan et al. 1989, Peters \& Grogan 1988, Mersky \& Mathew 1987). The increased effectiveness of mandatory recycling programs may be due to several factors: extra publicity as a result of passing a recycling ordinance; government commitment to the program indicated by making recycling mandatory; increased effectiveness of promotion and educational efforts; and enforcement of the ordinance through fines, refusal to pick up MSW or warnings (Glenn 1989b, Stone 1985, Fulginity 1985). It has also been shown that mandatory recycling programs tend to be started in areas with disposal problems (Everett 1989). Such areas are likely to have more mass media attention focused on MSW disposal and recycling, which may increase recycling material recovery by increasing perceptions of the magnitude of local disposal problems and the importance of recycling. Mandatory recycling has disadvantages: it taints the spirit of voluntary participation; mandatory programs receive greater scrutiny and more is expected of them, especially when they supersede a voluntary program; and enforcement can be difficult and expensive (Watson 1989, Walsh \& O'Leary 1988b). Many communities take a minimalist approach, rarely if at all enforcing their ordinance (Watson 1989, Cooper 1982); and there is disagreement on the effectiveness of this course of action (Glenn $1989 b$, Long 1989, Walsh \& O'Leary 1988b).

\subsection{Convenience}

Given that the goals of a RCRP are generally known (through contact and promotion) and approved of (ideological agreement), an additional factor in encouraging participation is the cost of participation. Making participation more convenient reduces personal cost, and thus should increase participation. Convenience is cited as an important factor related to participation in RCRPs (Glenn 1989a, Hageman 1989, O'Leary \& Walsh 1988). Conversely, perceived inconvenience is cited as an important reason for not recycling (Vining \& Ebreo 1990, De Young 1988-1989, 1990). Factors mentioned in the literature include provision of containers, and collection frequency and day.

\subsubsection{Containers}

Providing containers free of charge increases convenience and provides a visual reminder to recycle (Allen et al. 1989, Hageman 1989, Pieters 1986, Jacobs et al. 1984). Uniform containers also provide peer pressure as container absence on collection day clearly identifies non-recyclers. It is generally believed that RCRP participation and recovery is improved by containers (Schmerling 1990, Gilitz 1989). Rigid containers appear to be the most convenient and produce the highest recovery, however, they are expensive and can represent a significant start-up cost (Gilitz 1989, Stroessner 1988).

\subsubsection{Collection frequency and day}

Collection frequency and day may relate to convenience. As recyclables are picked-up more frequently, convenience may be increased because: materials are stored in the home for less time; recyclers have more opportunity to recycle; and if one pick-up day is missed the wait for the next is shorter and the extra build-up of materials less. Material recovery has been noted to increase with collection frequency (Proemba \& Vick 1990, Spurr 1988, Mersky 1988, Foran 1987, Jacobs \& Bailey 1982-1983). Collecting 
recyciables on the same day as MSW may be more convenient because it is easier for recyclers to remember to recycle on the day they already put out their MSW (Foran 1987, Jacobs et al. 1984). However, there have been mixed results (Dawson \& Pines 1984). A possible explanation is that, for programs not collecting recyclables every week, but collecting MSW every week, participants must still remember what week to recycle. This is probably more difficult than remembering what day to recycle. Thus, same day collection may be more convenient when recyclables collection is every week, but not when collection is once every 2 or 4 weeks.

Collection frequency is directly related to program cost (Stevens 1988). Determining the cost effectiveness of frequency will greatly aid program designers. Both collection frequency and day consideration are important in coordinating MSW and recyclable collection schedules. If same day as MSW collection is not effective or frequency not important then communities will have more scheduling freedom.

\section{Hypotheses}

Three hypotheses are tested concerning mandatory participation:

(1) RCRPs requiring participation collect more materials than those which do not;

(2) RCRPs enforcing punishments collect more materials than RCRPs which do not enforce punishments, which in turn collect more materials than RCRPs which do not make participation mandatory; and

(3) RCRPs switching from voluntary to mandatory participation in a given time period achieve higher collection increases than programs remaining voluntary through the same period.

Three hypotheses are tested concerning recycling convenience:

(4) RCRPs providing a container collect more material than those that do not;

(5) RCRPs collecting materials more frequently collect more material; and

(6) RCRPs collecting recyclables on the same day as MSW collect more material.

\section{Questionnaire method, measurement and statistical analyses}

A questionnaire of U.S. residential curbside recycling programs was administered following procedures outlined in Dillman (1978). A search of 49 states, excluding Oregon, was conducted to identify residential curbside recycling programs. The addresses of over 1200 programs were obtained. Twelve hundred and thirty five surveys were mailed and 631 returned, a return success rate of $51.1 \%$. In the surveys returned, 274 were for programs that had not yet started, no longer existed, were drop off only or incorrect addresses, leaving 357 completed surveys. All programs which returned surveys or which indicated interest in our results received a report presenting preliminary results produced from the data collected by the survey.

Program success was measured using the annual per capita material recovery rates (MRR) of newspaper, glass and aluminum, separately, defined by the National Recycling Coalition (1989) as the material recovered in 12 consecutive months divided by the population served. Both material collection amount and population served were obtained from the programs and may contain errors. Newspaper, glass and aluminum were chosen as they are the most commonly collected materials. MRRs were collected for 1987 and 1988. The survey question used to gather information on material amounts asked recycling coordinators to provide the amount collected in each year. The "amount 
collected" reported by recycling coordinators might be the amount collected from residents, for example, of newspaper, including contaminants inadvertently placed with the newspaper by residents. Alternatively, it might be the amount delivered to market as newspaper - probably containing less contaminants after some processing, such as hand sorting. It is also important to note that MRR does not take into account geographical, economic or urban versus rural differences in the availability of recyclable materials. The composition of MSW varies from place to place, thus, the MSW of one community may contain more newspaper, for example, than another community. A higher newspaper MRR in the first community might be the result of more available newspaper, not more recycling activity. This inserts some uncertainty into the analyses undertaken in this paper. However, as this information does not exist for the majority of programs, MRR is the best available measure of success. It has been used in a similar analysis by McGrath (1990). Participation rate is an alternative measure of success, and can be useful tracking single programs temporally or spatially, though the measure suffers from some problems (Smedburg 1989, Powell 1989). It is not necessarily a useful measure for inter-program comparison, however, because programs measure it using different methods, which vary widely in accuracy and precision. The subject of measuring recycling program success has been addressed by the authors elsewhere (Everett $\&$ Peirce 1992a).

Finally, the U.S.A. has nine states where beverage containers are subject to deposit. One deposil state, Oregon, also has statewide curbside recycling in communities over a certain size. Oregon programs collect materials such as newspaper, plastics, cardboard and food containers. However, Oregon was the one state excluded from this study, mainly because the curbside programs are primarily run by local private haulers, often more than one to a community. State officials informed the authors early in the study that it was unlikely that these companies would answer survey questions, plus it would have been difficult to determine the populations served by haulers in communities served by more than one. Other deposit states had little curbside recycling activity in 1987 and 1988. The few programs in deposit state which returned questionnaires predominately collected newspaper only, which does not have a deposit.

The response variables (MRR for newspaper, glass and aluminum) are continuous. The explanatory variables (legality and convenience) are all categorical or ordinal. The explanatory variables split the sample into groups. The appropriate statistical tests to examine differences between means are thus $t$-tests for dichotomous explanatory variables and general linear model analysis of variance for explanatory variables of more than two values. The overall statistical significance of the differences are reported as well as Duncan's multiple range test for statistically significant differences between groupings (Bethea et al. 1985).

\section{Results}

No collection costs are included in this report. The survey method used to gather information is not suitable for gathering detailed economic information. Furthermore, many programs either do not keep detailed information, do not want to give it out, or have difficulty separating costs; for example, wages paid to laborers working on, or maintenance costs of, trucks used for both MSW and recyclable collection. Economic information is best calculated on a case basis.

Information on revenues for materials was collected. However, markets in the U.S.A. have not been stable, so 1988 data may not reflect the current situation. The average price received for newspaper, glass and aluminum in 1988 , reported by the programs 
TABLE 1

General information on material recovery rate in 1988 for survey respondents

\begin{tabular}{|c|c|c|c|c|}
\hline $\begin{array}{l}\text { Recyclable } \\
\text { material }\end{array}$ & $\begin{array}{c}\text { MRR mean } \\
\text { [lb/person } \\
(\mathrm{kg} / \text { person })]\end{array}$ & $\begin{array}{l}\text { MRR S.D. } \\
\text { [lb/person } \\
\text { (kg/person)] }\end{array}$ & $\begin{array}{l}\text { Number of } \\
\text { programs } \\
\text { collecting } \\
\text { each material }\end{array}$ & $\begin{array}{c}\text { Percentage } \\
\text { total } \\
\text { number of } \\
\text { programs }\end{array}$ \\
\hline Newspaper & $\begin{array}{c}90 \\
(41)\end{array}$ & $\begin{array}{c}49 \\
(22)\end{array}$ & 344 & $96 \%$ \\
\hline Glass & $\begin{array}{c}31 \\
(14)\end{array}$ & $\begin{array}{l}23 \\
(10)\end{array}$ & 219 & $61 \%$ \\
\hline Aluminum & $\begin{array}{c}2.6 \\
(1.1)\end{array}$ & $\begin{array}{c}2.9 \\
(1.3)\end{array}$ & 205 & $57 \%$ \\
\hline
\end{tabular}

Note: 359 respondents.

responding to the questionnaire, was 16,37 and $969 \$$ ton, respectively. These figures varied inter and intra-regionally. Newspaper prices in particular varied, ranging as low as $-22 \$ /$ ton, meaning that some recycling programs paid recyclers to take their newspaper.

Table 1 presents general information concerning recovery rates reported by the survey respondents. The standard deviations for the MRRs of newspaper, glass and aluminum are large, indicating the wide variability of MRR reported by the survey respondents. Almost all of the programs collect newspaper (96\%), while 61 and $57 \%$ collect glass and aluminum, respectively. Participation requirement has the strongest effect on MRR. Table 2 shows MRR for programs split into two groups: those mandating participation and those leaving participation voluntary. For each material, mandatory participation programs have higher average MRR: $50 \%$ higher for newspaper, 100\% higher for glass and $12 \%$ higher for aluminum.

The effect of enforcement is less clear (Table 3). Newspaper shows a significant increase in mean MRR going from no punishments (voluntary participation), to unenforced punishments, to enforced punishments. Aluminum increases in much the same manner as newspaper, but not significantly. Glass mean MRR, however, shows a significant difference only between punishment (unenforced or enforced) and no

TABLE 2

Material recovery rate versus participation - voluntary or mandatory

\begin{tabular}{lccc}
\hline Recyclable & $\begin{array}{c}\text { Mandatory } \\
\text { participation } \\
\text { [Mean MRR, } \\
\text { material }\end{array}$ & $\begin{array}{c}\text { Voluntary } \\
\text { participation } \\
\text { [Merson } \\
\text { [Mean MRR, } \\
\text { 1b/person } \\
(\mathrm{kg} / \text { person)] }\end{array}$ & $\begin{array}{c}\text { Statistical } \\
\text { significance }\end{array}$ \\
\hline Newspaper & 103 & 70 & $P<0.001$ \\
Glass & $(47)$ & $(32)$ & $P<0.001$ \\
Aluminum & 43 & 22 & - \\
& $(19)$ & $(10)$ & \\
\hline
\end{tabular}


TABLE 3

Material recovery rate versus punishment - enforced, not enforced or none

\begin{tabular}{lcccc}
\hline Recyclable & $\begin{array}{c}\text { Punishments } \\
\text { enforced } \\
\text { [Mean MRR, } \\
\text { 1b/person } \\
\text { material }\end{array}$ & $\begin{array}{c}\text { Punishments } \\
\text { not enforced } \\
\text { [Mean MRR, } \\
\text { lb/person } \\
\text { (kg/person) }\end{array}$ & $\begin{array}{c}\text { No } \\
\text { punishments } \\
\text { [Mean MRR, } \\
\text { lb/person } \\
(\mathrm{kg} / \text { person) })\end{array}$ & $\begin{array}{c}\text { Statistical } \\
\text { significance }\end{array}$ \\
\hline Newspaper & 115 & 99 & 71 & $P<0.001$ \\
Glass & $(52)$ & $(45)$ & $(32)$ & $P<0.001$ \\
Aluminum & 42 & 41 & 24 & - \\
& $(19)$ & $(18)$ & $(11)$ & 2.3 \\
\hline
\end{tabular}

Note: by Duncan's multiple range test (see Bethea et al. 1985), columns 2, 3 and 4 significantly differ for newspaper, and columns 2 and 3 significantly differ from column 4 for glass.

punishment. It is difficult to explain this result. Many participants do not recycle all materials, typically more recycle newspaper than other materials (Smedburg 1988, Glenn 1988). It is possible that some factors, such as requiring participation or using punishments, affect material recovery differently for different materials. Newspaper and aluminum do not require cleaning, while some glass containers may require rinsing before storage, awaiting collection. Perhaps enforcement motivates more residents to recycling newspaper and aluminum, but not glass, due to this extra inconvenience. Programs which switched from voluntary to mandatory participation in 1987 or 1988 experienced higher increases in mean MRR than programs which remained voluntary through that period (Table 4). Differences for newspaper and glass are significant.

\section{TABLE 4}

Difference between material recovery rate measured in 1988 and 1987 , comparing programs which became mandatory during that time to those which remained voluntary

\begin{tabular}{lccc}
\hline & $\begin{array}{c}\text { Progams which } \\
\text { switched to } \\
\text { mandatory } \\
\text { participation in } \\
\text { 1987 or 1988 } \\
\text { [Mean MRR } \\
\text { difference, } \\
\text { lb/person } \\
(\mathrm{kg} / \text { person) }\end{array}$ & $\begin{array}{c}\text { Programs which } \\
\text { kept voluntary } \\
\text { participation } \\
\text { through 1988 } \\
\text { [Mean MRR } \\
\text { difference, } \\
\text { Ib/person } \\
\text { (kg/person) }\end{array}$ & \\
Recyclable & $\begin{array}{c}\text { Statistical } \\
\text { significance }\end{array}$ \\
material & 33 & 13 & $P<0.01$ \\
Newspaper & $(15)$ & $(6)$ & $P<0.01$ \\
Glass & 17 & 4 & \\
Aluminum & $(8)$ & $(2)$ & - \\
& 1.1 & $(0.1)$ & \\
\hline
\end{tabular}


TABLE 5

Material recovery rate versus container provision for voluntary and mandatory participation programs

\begin{tabular}{|c|c|c|c|}
\hline $\begin{array}{l}\text { Recyclable } \\
\text { material }\end{array}$ & $\begin{array}{l}\text { No container } \\
\text { provided } \\
\text { [Mean MRR, } \\
\text { lb/person } \\
\text { (kg/person)] }\end{array}$ & $\begin{array}{c}\text { Container } \\
\text { provided } \\
\text { [Mean MRR, } \\
\text { lb/person } \\
(\mathrm{kg} / \text { person })]\end{array}$ & $\begin{array}{c}\text { Statistical } \\
\text { significance }\end{array}$ \\
\hline \multicolumn{4}{|c|}{ (a) Voluntary participation programs } \\
\hline Glass & $\begin{array}{l}17 \\
(8)\end{array}$ & $\begin{array}{c}25 \\
(11)\end{array}$ & $P<0.08$ \\
\hline Aluminum & $\begin{array}{c}1.8 \\
(0.8)\end{array}$ & $\begin{array}{l}2.8 \\
(1.3)\end{array}$ & - \\
\hline \multicolumn{4}{|c|}{ ipation programs } \\
\hline Glass & $\begin{array}{l}48 \\
(22)\end{array}$ & $\begin{array}{c}36 \\
(16)\end{array}$ & $P<0.07$ \\
\hline Aluminum & $\begin{array}{c}2.8 \\
(1.3)\end{array}$ & $\begin{array}{l}2.8 \\
(1.3)\end{array}$ & - \\
\hline
\end{tabular}

Several factors which may decrease the inconvenience associated with recycling are explored. Voluntary programs distributing containers free of charge recovered more glass and aluminum in 1988 than those which did not (Table 5). This was not found for mandatory programs. Mandatory RCRPs distributing containers free of charge recovered less glass and the same amount of aluminum as those which did not. However, no differences were significant at the 0.05 level. This interesting effect could be caused by some correlation of container provision with other, unknown factors. Perhaps unsuccessful mandatory programs are more likely to provide containers in an attempt to increase MRRs (that is low MRR encourages container provision). A review of the literature did not identify any explanations for this result. However, the study reported here is the only one known to the authors in which sufficient information, from a large enough number of programs, was collected to allow statistical comparisons.

Three collection frequencies for recovered materials are the most widely used in the U.S.A.: once per 4 week period ( $21 \%$ ); twice per 4 week period ( $39 \%)$; and once per week $(38 \%)$. A small minority of programs $(2 \%)$ collected more or less frequently and these programs were excluded from analysis. RCRPs are divided almost equally between those collecting on the same day as MSW collection and those not collecting on the same day as MSW collection.

Programs collecting once a week collected the most newspaper and glass, but not aluminum, for which the highest MRR occurred for programs collecting twice every 4 weeks (Table 6). None of the relationships were significant at the 0.05 level. Elsewhere, the authors have shown that privately operated recycling programs tend to collect more aluminum than programs operated by government organizations (Everett \& Peirce $1991 b$ ). It is hypothesized that private companies, with stronger profit motives, exert more effort in collecting aluminum, a high revenue material. A greater percent, 37 versus 33 , of the programs collecting aluminum twice per 4 weeks versus those collecting once 
TABLE 6

Material recovery rate versus collection frequency

\begin{tabular}{|c|c|c|c|c|}
\hline $\begin{array}{l}\text { Recyclable } \\
\text { material }\end{array}$ & $\begin{array}{c}\text { Collection } \\
\text { once every } \\
4 \text { weeks } \\
\text { [Mean MRR, } \\
\text { lb/person } \\
\text { (kg/person)] }\end{array}$ & $\begin{array}{c}\text { Collection } \\
\text { twice every } \\
4 \text { weeks } \\
\text { [Mean MRR, } \\
\text { lb/person } \\
\text { (kg/person)] }\end{array}$ & $\begin{array}{c}\text { Collection } \\
\text { once each } \\
\text { week } \\
\text { [Mean MRR, } \\
\text { lb/person } \\
\text { (kg/person)] }\end{array}$ & $\begin{array}{c}\text { Statistical } \\
\text { significance }\end{array}$ \\
\hline Newspaper & $\begin{array}{c}86 \\
(39)\end{array}$ & $\begin{array}{c}86 \\
(39)\end{array}$ & $\begin{array}{c}96 \\
(43)\end{array}$ & - \\
\hline Glass & $\begin{array}{c}23 \\
(10)\end{array}$ & $\begin{array}{c}42 \\
(19)\end{array}$ & $\begin{array}{c}48 \\
(22)\end{array}$ & \\
\hline Aluminum & $\begin{array}{c}2.1 \\
(1.0)\end{array}$ & $\begin{array}{c}3.4 \\
(1.5)\end{array}$ & $\begin{array}{c}2.2 \\
(1.0)\end{array}$ & - \\
\hline
\end{tabular}

Note: all differences remain insignificant when programs are split into mandatory and voluntary participation groups.

per week are privately operated. However, this difference does not seem large enough to explain the difference in aluminum MRR of 3.4 versus 2.2 shown in Table 6 .

Collection day (Table 7) does not appear to affect MRR in the manner hypothesized. The only significant difference in mean MRR for groups split on collection day occurs for newspaper mean MRR and is in the opposite direction expected. It was suggested earlier that recyclables collection on the same day as MSW collection might be more effective for programs collecting once per week versus programs collecting less frequently. However, analyses conducted on programs separated into groups by collection frequency failed to demonstrate this. This result, though not statistically significant, is contradictory to results of most studies, published in the literature, in which two pilot programs are operated in a community, one with same day, one with different day

\section{TABLE 7}

Material recovery rate versus collection day

\begin{tabular}{lccc}
\hline Recyclable & $\begin{array}{c}\text { Not on the same } \\
\text { day as MSW } \\
\text { collection } \\
\text { [Mean MRR, } \\
\text { Ib/person } \\
\text { material }\end{array}$ & $\begin{array}{c}\text { On the same day } \\
\text { as MSW } \\
\text { collection } \\
\text { [Mean MRR, } \\
\text { lb/person } \\
(\mathrm{kg} / \text { person)] }\end{array}$ & $\begin{array}{c}\text { Statistical } \\
\text { significance }\end{array}$ \\
\hline Newspaper & 98 & 83 & $P<0.02$ \\
Glass & $(44)$ & $(38)$ & - \\
Aluminum & 34 & 30 & - \\
& $(15)$ & $(14)$ & \\
\hline
\end{tabular}

Note: these general relationships are repeated when programs are split on the basis of voluntary and mandatory participation. The only significant difference is for newspaper mandatory participation (113 versus $94 ; P<0.03$ ). 
TABLE 8

Apparent trends in material recovery rates

\begin{tabular}{|c|c|}
\hline Program characteristic & Apparent trend \\
\hline Participation requirement & $\begin{array}{l}\text { Programs with a mandatory participation requirement } \\
\text { collected more material in } 1988 \text { than programs with } \\
\text { voluntary participation. Switching from voluntary to } \\
\text { mandatory participation appears to increase collections. } \\
\text { Enforcing mandatory participation requirements may be } \\
\text { effective depending on the material and, of course, on the } \\
\text { cost. }\end{array}$ \\
\hline Container provision & $\begin{array}{l}\text { Container provision is associated with higher collection for } \\
\text { voluntary programs, but lower collection for mandatory } \\
\text { programs. }\end{array}$ \\
\hline Collection frequency & $\begin{array}{l}\text { Higher collections tend to be associated with higher } \\
\text { collection frequency, however, the trend is a small one. } \\
\text { Collection frequency should probably be based on how } \\
\text { much material residents are expected to separate and store, } \\
\text { rather than convenience. }\end{array}$ \\
\hline Collection day & $\begin{array}{l}\text { Higher collections are associated with different collection } \\
\text { day, contrary to expectation. However, the trends were } \\
\text { small. }\end{array}$ \\
\hline
\end{tabular}

collection. In these studies, same day collection typically results in larger collections. Unknown factors may be the cause of the result reported here. Perhaps same day programs tend to expend less effort on education and promotion than different day programs, because communities where interest in recycling is low opt for same day collection as the easiest way to provide curbside service.

The collection frequency and day relationships shown in Tables 6 and 7 remain when analyses are conducted on programs separated into mandatory and voluntary groups. It appears that collection frequency, at least in the range tested here, has a small, but not statistically significant, affect on MRR for glass and newspaper. It also appears that collection day has no positive effect. However, collection day may be associated with other program characteristics which obscure any significant relationships, for example publicity levels or program budget. This possibility could not be tested with the available data.

\section{Conclusions}

A list of apparent trends is shown in Table 8.

(1) RCRPs requiring participation collect more material than those which do not. The mandatory participation programs responding to the questionnaire collected $50 \%$ more newspaper, $100 \%$ more glass and $12 \%$ more aluminum than voluntary programs, based on MRRs. However, it is not clear whether this is due to law abiding behavior patterns, increased publicity associated with passing mandatory ordinances, extra perceived seriousness of mandatory programs, or a correlation with mass media attention concerning MSW disposal problems and recycling necessity. 
(2) The effect of enforcing mandatory participation with punishments is not as clear. Mandatory RCRPs, whether punishments are enforced or not, have higher MRRs. But comparisons of RCRPs enforcing punishments to those not enforcing punishments show two different effects. RCRPs enforcing mandatory participation have higher MRRs for newspaper and aluminum (significant at 0.05 level for newspaper) than RCRPs not enforcing mandatory participation. However, glass MRRs for mandatory programs are almost identical, whether punishments are enforced or not.

(3) Making participation mandatory after operating as a voluntary RCRP appears to increase MRRs for newspaper, glass and possibly aluminum. For RCRPs responding to the survey, comparisons of differences betwen 1988 and 1987 MRRs for RCRPs switching to mandatory participation during that time period and RCRPs which remained voluntary, found that switching RCRPs collected $150 \%$ more newspaper, $325 \%$ more glass and $270 \%$ more aluminum than RCRPs which remained voluntary.

(4) The provision of containers may increase MRRs for voluntary participation RCRPs; however, the differences were not statistically different at the 0.05 level. The data show no support for container provision for mandatory participation RCRPs; the glass MRR dropped with container provision, while the aluminum MRR remained constant.

(5) Collection frequency appears to have little affect on average MRRs for the materials investigated for the three most common collection frequencies. Once a week collection is associated with the highest MRRs for newspaper and glass, while the highest MRR for aluminum is associated with collection twice every 4 weeks. None of the differences were significant at the 0.05 level.

(6) Collection on the same day as MSW collection appears to have detrimental effect on average MRRs. RCRPs collecting recyclables on the same day as MSW actually achieved lower MRRs for all materials (significant at the 0.05 level for newspaper).

(7) The results of this study can be applied to the design of residential curbside recycling programs. The figures presented in this paper can be used as rough estimates for design purposes. Mandatory RCRPs collect more materials than voluntary RCRPs. Enforcement tends to increase MRRs, especially for newspaper. Mandatory participation appears to be the most significant program parameter. The provision of containers seem to be effective for voluntary RCRPs, but may not be for mandatory RCRPs, though this effect may be caused by unsuccessful mandatory programs supplying containers in an attempt to increase recovery. Collection frequency and day do not appear to be important design parameters. Collection frequency did increase MRR, but not in a statistically significant manner. Collection on the same day as MSW actually is associated with lower MRR. Therefore, RCRP designers should concentrate on fitting the recycling program collection schedule into the existing MSW collection schedule in a cost effective manner rather than maximizing collection frequency or scheduling collection on the same day as MSW collection. For example, replacing one MSW collection with a recyclable material collection may be advantageous.

(8) The findings on container provision, collection frequency and collection day are at odds with some observations of recycling coordinators reported in the literature. Re-testing the hypotheses with more data, especially as some relationships were not significant, may shed more light on the issues. Furthermore, other variables 
which may confound the relationships should be investigated, such as total number of materials collected, program budget, promotion levels, education and income levels of served populations, and home ownership to name a few possibilities. Finally, surveys of individuals may provide more detailed information in these areas.

\section{Acknowledgements}

The authors wish to thank the recycling coordinators who took the time and effort to fill out the questionnaire and the National Science Foundation for support of this project. In particular, we gratefully acknowledge the Presidential Young Investigator Award Program and Dr Edward Bryan in the National Science Foundation Environmental Engineering Division.

\section{References}

Allan, T., Pratt, B. \& Morris, D. (1989) Beyond 25 Percent: Materials Recovery Comes of Age. Washington D.C., U.S.A.: Institute for Local Self-Reliance.

ASTSWMO (1987) Disposal crisis coming? state-by-state answers. Waste Age 18(1) 57-64.

Bell, R., Grogan, P. \& Schwartz, B. (1990) Legislative Evaluation: federal, state and local government. Paper presented at the 1990 Pennsylvania Recycling Conference on Waste Reduction and Recycling, Camp Hill, PA, U.S.A.

Bethea, R., Duran, B. \& Boullion, T. (1985) Statistical Methods for Engineers and Scientists. New York, U.S.A.: Marcel Dekker, Inc.

Cooper, R. M. (1982) A survey of mandatory recycling ordinances. Resource Recovery 1(2), 12-13, 27.

Dawson, C. \& Pines, C. (1984) Risking success: recycling in St Luis Park, Minnesota. Resource Recycling 3(1), 22-23, 30-31.

De Young, R. (1988-1989) Exploring the difference between recyclers and non-recyclers: the role of information. Journal of Environmental Systems 18(4), 341-351.

De Young, R. (1990) Recycling as appropriate behavior: a review of survey data from selected recycling education programs in Michigan. Resources, Conservation and Recycling 3, 253266.

Dillman, D. (1978) Mail and Telephone Surveys: The Total Design Method. New York, U.S.A.: Wiley.

Everett, J. (1989) Residential recycling programs: environmental, economic and disposal factors. Waste Management \& Research 7, 143-152.

Everett, J. \& Peirce, J. J. (1991a) Recycling promotion strategies: statistical and fuzzy set comparisons. Journal of Urban Planning and Development, ASCE 117(4), 154-167.

Everett, J. \& Peirce, J. J. (1991b) National analysis of recycling material recovery rates. Journal of Resource Management and Technology 19(4), 148-152.

Everett, J. \& Peirce, J. J. (1992a) Mcasuring the success of recycling programs. Resources Conservation and Recycling 6, 355-370.

Everett, J. \& Peirce, J. J. (1992b) Social networks, socioeconomic status, and environmental collective action: residential curbside block leader recycling. Journal of Environmental Systems 21(1), 65-84.

Foran, B. (1987) 1986-87 Oregon/California residential curbside recycling survey report. Eugene, OR, U.S.A.: Lane County Waste Management Division.

Fulginity, J. R. (1985) Taking the myths out of curbside collection. Biocycle 26(6), 24-27.

Gilitz, J. (1989 Curbside collection containers, a comparative evaluation. Resource Recycling 7(7), $20-22,51$.

Glenn, J. (1988) Junior, take out the recyclables. Biocycle 29(5), 26-31.

Glenn, J. (1989a) 'New age' drop off programs. Biocycle 30(2), 42-43.

Glenn, J. (1989b) Enforcing mandatory recycling ordinances. Biocycle 30(3), 31-31, 36.

Glenn, J. (1990) The state of garbage in America. Biocycle 31(4), 34-41.

Glenn, J. \& Riggle, D. (1991) The state or garbage in America. Biocycle 32(4), 34-38. 
Hageman, K. (1989) How to make a good recycling program better. Biocycle 30(4), 62-64.

Jacobs, H. \& Bailey, J. (1982-1983) Evaluating participation in a residential recycling program. Journal of Environmental Systems 12(2).

Jacobs, H. \& Bailey, J. (1982-1983) Evaluating participation in a residential recycling program. Journal of Environmental Systems 12(2), 141-152.

Long, L. (1989 How to get results in residential recycling. Biocycle 30(8), 76-77.

Lund, J. (1990) Least-cost scheduling of solid waste recycling. Journal of Environmental Engineering 116(1), 182-197.

McGrath, S. (1990) Analysis of recycling recovery rates. Journal of Resource Management and Technology 18(1), 2-10.

Mersky, R. (1988) Basic design parameters for recycling programe. Journal of Resource Management and Technology 16(2), 104-107.

Mersky, R. \& Mathew, K. (1987) Recycling opinion survey. Resource Recycling 6(2), 25, 50.

National Recycling Coalition (1989) The National Recycling Coalition measurement standards and reporting guidelines, draft. Washington, D.C., U.S.A.: National Recycling Coalition.

O'Leary, P. \& Walsh, P. (1988) How to make a voluntary program work. Waste Age 19(5), 98194.

Peters, A. \& Grogan, P. (1988) Community recycling. Biocycle 29(5), 32-36.

Pieters, R. (1986) Participation in source separation projects: design characteristics and perceived costs and benefits. Resources and Conservation 12(2), 95-111.

Powell, J. (1989) All those surveys can help recycling. Resource Recycling 8(7), 25, 67-68.

Schmerling, E. (1990) Recycling container choices. Biocycle 31(3), 36-37.

Smedberg, J. (1989) Calculating participation: a look at that tricky multiplier. Resource Recycling $8(6), 26-27,64$.

Spurr, M. (1988) Curbside sampling of recyclables. Resource Recycling 7(5), 26-29.

Stevens, B. (1988) Cost analysis of curbside programs. Biocycle 29(5), 3738.

Stone, D. (1985) Curbside in California. Biocycle 26(4), 53-54.

Stroessner, W. (1988) Small town recycling. Resource Recycling 7(1), 18-19, 52-53.

USEPA (1989) Promoting source reduction and recyclability in the market place. EPA 530-SW89-066. Cincinnati, U.S.A.: U.S. Environmental Protection Agency.

Vining, J. \& Ebreo, A. (1990) What makes a recycler? A comparison of recyclers and nonrecyclers. Environment and Behavior 22(1), 55-73.

Walsh, P. \& O'Leary, P. (1988) Recycling offers benefits, opportunities ... and challenges. Waste Age 19(1), 54-60.

Walsh, P. \& O'Leary, P. (1988) How to implement a mandatory recycling program. Waste Age 19(6), 65-70.

Watson, T. (1989) The garbage police. Resource Recycling 8(3), 32-33, 58-62. 